\title{
Effects of light-to-moderate alcohol consumption on steatosis and steatohepatitis in severely obese patients
}

\author{
Helma P. Cotrim ${ }^{a}$, Luiz Antônio Freitas ${ }^{b}$, Erivaldo Alves ${ }^{c}$, Alessandro Almeida $^{a}$, \\ Daniel S. May a and Stephen Caldwell ${ }^{\mathrm{d}}$
}

Objectives The effect of light-to-moderate alcohol consumption (LMAC) in nonalcoholic fatty liver disease (NAFLD) remains a controversial subject. The aim of this study was to evaluate the relationship between LMAC and the severity of NAFLD in morbidly obese patients.

Methods We studied 132 patients undergoing liver biopsy during bariatric surgery. The patients were divided into three groups: G1: alcohol intake greater than $20 \mathrm{~g} /$ day and less than $\mathbf{4 0} \mathrm{g} /$ day; G2: alcohol intake less than $20 \mathrm{~g} /$ day; G3: no alcohol intake. Insulin resistance was defined by the Homeostasis Model Assessment ( $>3$ ). NAFLD was classified according to the Matteoni types: type I: steatosis alone; type II: steatosis with inflammation; types III-IV: steatosis with ballooning and/or fibrosis.

Results The mean age was $37.3 \pm 11$ years. Sixty-three percent were females and body mass index was $43.9 \pm 5.6 \mathrm{~kg} / \mathrm{m}^{2} . \mathrm{G} 1, \mathrm{G} 2$, and G3 included 19,56 , and 57 patients, respectively. Histological diagnoses classified by levels of alcohol were: G1: $10.5 \%$ normal liver, $89.5 \%$ type III or IV; G2: $10.7 \%$ normal liver, $1.8 \%$ type I or II, and $\mathbf{8 7 . 5 \%}$ grade III or IV; G3: $10.5 \%$ normal liver, $3.5 \%$ type I or II, and $\mathbf{8 6 \%}$ type III or IV (one had cirrhosis). The presence of IR was similar in moderate and no alcohol consumption (81.3 and $78.7 \%$ ) but significantly less in the light consumption group (54\%, $P<0.05)$.

Conclusion The results suggest that LMAC may have a protection effect against IR in severely obese patients. However, it had no impact on the severity of activity and stage of liver disease. Eur J Gastroenterol Hepatol 21:969-972 (c) 2009 Wolters Kluwer Health | Lippincott Williams \& Wilkins.

European Journal of Gastroenterology \& Hepatology 2009, 21:969-972

Keywords: alcoholic liver disease, insulin resistance, nonalcoholic fatty liver disease, obesity

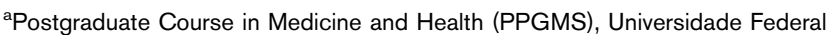
da Bahia (UFBA), ${ }^{b}$ Centro de Pesquisa Gonçalo Muniz, Fundação Osvaldo Cruz-CPqGMS (FIOCRUZ), ' Center for the Surgical Treatment of Obesity, Bahia, Brazil and dDivision of Gl/Hepatology, University of Virginia, Charlottesville, USA

Correspondence to Helma P. Cotrim, MD, PhD, Programa de Pós Graduação em Medicina e Saúde, PPGMS Rua Padre Feijó, 240 Ambulatório Magalhães Neto, 3 Andar, Salvador, Bahia CEP 40110-170, Brazil

Tel/fax: +55 713276 2373; e-mail: hpcotrim@ufba.br

Received 12 September 2008 Accepted 26 December 2008

\section{Introduction}

Obesity is epidemic worldwide and its prevalence has been increasing in most countries in recent decades [1-4]. Obesity is an independent risk factor for cardiovascular disease and it is associated with other independent risk factors such as hypertension, hyperlipidemia, impaired glucose tolerance, and metabolic syndrome (MS) [5]. Obesity is also an important risk factor of nonalcoholic fatty liver disease (NAFLD) and it has been considered a predictor of the severity of this condition. Histologically, NAFLD is virtually identical to alcoholic liver disease, but it occurs in individuals without a history of heavy alcohol intake. Moderate alcohol consumption has been associated with reduced cardiovascular disease and it has been attributed to a more favorable lipid profile and less thrombogenic platelet function [6]. It also has been associated with favorable changes in glucose metabolism, improved insulin activity, and a lower prevalence of type II diabetes in severely obese patients [6,7].
Recently, we have studied the clinical spectrum of NAFLD in severe obese NAFLD patients. We observed that $70 \%$ of them were asymptomatic and presented with normal aminotransferases and ultrasound. However, liver biopsies taken during bariatric surgery showed that these patients presented with a wide spectrum of liver alterations related to NAFLD and that nonalcoholic steatohepatitis (NASH) with a variable degree of fibrosis was a frequent finding [8]. In this study, we have evaluated the association between abstinence and lightto-moderate alcohol consumption and the severity of NAFLD in obese patients undergoing bariatric surgery.

\section{Patients and methods Study design}

A cross-sectional study was carried out on consecutive patients with severe obesity, who underwent liver biopsy during bariatric surgery from October 2004 to April 2005. The eligible criteria for inclusion were: age above 
18 years, preoperative abdominal ultrasound, and liver biopsy performed during the surgery. All patients had body mass index above $40 \mathrm{~kg} / \mathrm{m}^{2}$, or above $35 \mathrm{~kg} / \mathrm{m}^{2}$ associated with other conditions (hypertension, diabetes, hyperlipidemia or sleep apnea). Patients with alcohol intake above $280 \mathrm{~g} /$ week ( $>40 \mathrm{~g} /$ day) or those who had other chronic liver diseases (HBV or HCV infection, hemochromatosis, autoimmune hepatitis, Wilson's disease, primary biliary cirrhosis, $\alpha$-1-antitrypsin deficiency) were excluded.

This study was carried out in accordance with a protocol approved by the Ethics Committee for Medical Research of Gonçalo Moniz Research Center (Oswaldo Cruz Foundation, Brazilian Health Minister). All of the patients included have consented to their participation in this study.

\section{Clinical evaluation}

The parameters studied included: age, sex, height, weight, waist circumference, history of hypertension, hyperlipidemia, diabetes, exposure to petrochemicals and drugs used. Laboratory evaluation included: hemoglobin, hematocrit, leukocytes, prothrombin time, aminotransferases (alanine aminotransferase and aspartate aminotransferase), total bilirubin, albumin, total cholesterol, HDL-cholesterol, triglycerides, fasting plasma glucose, and insulin levels. Abdominal ultrasound was performed in all patients. Insulin resistance (IR) was calculated using Homeostasis Model Assessment Index of Insulin Resistance (HOMA-I). Patients were categorized as insulin resistant if the Homeostasis Model Assessment Index of IR value was equal or greater than 3.0, as previously described [9].

The patients were classified into three groups according to alcohol consumption: G1: alcohol intake greater than $20 \mathrm{~g} /$ day and less than $40 \mathrm{~g} /$ day; G2: alcohol intake less than $20 \mathrm{~g} /$ day; $\mathrm{G} 3$ : no alcohol intake. The pattern of alcohol consumption was determined by the physician's interview and by interview with the patient's relatives.

\section{Liver biopsy and histological analysis}

A wedge biopsy was obtained at the beginning of the surgical procedure performed laparoscopically. All samples were processed and examined by the same pathologist (L.A.F.) who was unaware of the estimated alcohol consumption. Histological sections were stained with hematoxylin and eosin, Sirius red for collagen, and Perl's stain for iron. Biopsies were scored and classified according to the types previously reported by Matteoni et al. [10] as isolated steatosis (type I); steatosis + inflammation (type II); steatohepatitis - (steatosis and ballooning of hepatocytes) (type III) or steatohepatitis with fibrosis (type IV). Grading and staging for NAFLD and NASH took into account the same criteria previously published by Brunt $e t$ al. [11] and Kleiner $e t$ al. [12].

\section{Statistical analysis}

Data were processed and analyzed using the Statistical Package for the Social Sciences software program, Version 13.0 (SPSS Inc., Chicago, Illinois, USA). The results of the continuous variables were presented in the form of mean \pm standard deviation added to the median and interquartile range when the variable did not have a normal distribution. The variable categories were expressed as absolute and relative frequencies. Frequencies were compared by using $\chi^{2}$ tests. All statistics were twotailed and the level of significance was set at a $P$ value of less than 0.05 .

\section{Results}

The sample was composed of 132 patients (91 female and 41 male). The mean age was $37.27 \pm 11.06(18-65)$ years and a mean body mass index was $43.9 \pm 5.6 \mathrm{~kg} / \mathrm{m}^{2}$. Overall, $14(10.6 \%)$ patients had no steatosis, whereas the others had histological classification: type I: one $(0.8 \%)$; type II: two $(1.5 \%)$; type III: $16(12.1 \%)$; and type IV: 99 (75\%). One patient from G3 had cirrhosis.

Table 1 Clinical profile of each studied group

\begin{tabular}{|c|c|c|c|c|}
\hline Characteristics & G1 $(n=19)$ & G2 $(n=56)$ & G3 $(n=57)$ & Total $(N=132)$ \\
\hline Age, mean \pm SD (years) & $36.5 \pm 11.4$ & $36.4 \pm 9.8$ & $38.0 \pm 11.9$ & $37.3 \pm 11$ \\
\hline Female, $n(\%)$ & $5(26.3)$ & $43(76.8)$ & $43(75.4)$ & $91(68.9)$ \\
\hline Hypertension, $n(\%)$ & $8(42.1)$ & $29(51.8)$ & $30(52.6)$ & $67(50.8)$ \\
\hline Dislipidemia, $n(\%)$ & $16(84.2)$ & $36(64.3)$ & $42(73.7)$ & $94(71.2)$ \\
\hline Diabetes, $n(\%)$ & $3(15.8)$ & $7(12.5)$ & $6(10.5)$ & $16(12.1)$ \\
\hline Steatosis on ultrasound, $n(\%)$ & $12(63.2)$ & $33(58.9)$ & $29(50.9)$ & $74(56.1)$ \\
\hline Exposure to chemicals, $n(\%)$ & $5(26.3)$ & $4(7.1)$ & $7(12.3)$ & $16(12.1)$ \\
\hline Elevated WC, $n(\%)$ & $19(100)$ & $56(100)$ & $57(100)$ & $132(100)$ \\
\hline $\mathrm{BMI}$, mean $\pm \mathrm{SD}$ & $45.6 \pm 8.5$ & $44.0 \pm 5.6$ & $43.5 \pm 4.6$ & $44.0 \pm 5.7$ \\
\hline AST, median (IQR) & $30(20-43)$ & $23(19-32.7)$ & $24(19-30.5)$ & $24(19-32)$ \\
\hline ALT, median (IQR) & $48(33-82)$ & $30(19-49.5)$ & $35(26-46)$ & $33(24-50)$ \\
\hline GGT, median (IQR) & $61.5(36.6-81.7)$ & $35(26.8-55.2)$ & $40(30.6-56)$ & $39.1(29-60.5)$ \\
\hline HOMA, median (IQR) & $3.7(2.4-5.0)$ & $2.3(0-4.5)$ & $4.2(1.6-6.5)$ & $3.1(1.6-5.7)$ \\
\hline
\end{tabular}

ALT, alanine aminotransferase; AST, aspartate aminotransferase; BMI, body mass index; GGT, $\gamma$-glutamyltransferase; HOMA, Homeostasis Model Assessment; IQR, interquartile range; SD, standard deviation; WC, waist circumference. 
Table 2 ETCG versus NAFLD type $(N=132)$

\begin{tabular}{lccccc}
\hline Histology & Normal (\%) & Type I (\%) & Type II (\%) & Type III (\%) & Type IV (\%) \\
\hline ETCG & & & & & \\
G1 & 10.5 & 0 & 0 & 21.1 & 68.4 \\
G2 & 10.7 & 0 & 1.8 & 12.5 & 75.0 \\
G3 & 10.5 & 1.8 & 1.8 & 8.8 & 77.2 \\
\hline
\end{tabular}

ETCG, ethanol consumption group; NAFLD, nonalcoholic fatty liver disease. $P=0.89$.

Table 3 ETCG versus IR $(N=102)$

\begin{tabular}{lcc}
\hline ETCG & Without IR $n(\%)$ & With IR $n(\%)$ \\
\hline G1 & $3(18.8)$ & $13(81.3)$ \\
G2 & $21(53.8)$ & $18(46.2)$ \\
G3 & $10(21.3)$ & $37(78.7)$ \\
\hline
\end{tabular}

ETCG, ethanol consumption group; IR, insulin resistance. $P=0.002$ (comparing $\mathrm{G} 1$ and $\mathrm{G} 3$ to $\mathrm{G} 2$ ).

Table 4 IR versus NAFLD type $(N=102)$

\begin{tabular}{lccccc}
\hline Histology & Normal (\%) & Type I (\%) & Type II (\%) & Type III (\%) & Type IV (\%) \\
\hline Without IR & 14.7 & 0 & 5.9 & 14.7 & 64.7 \\
With IR & 10.1 & 1.4 & 0 & 11.6 & 76.8 \\
\hline
\end{tabular}

IR, insulin resistance; NAFLD, nonalcoholic fatty liver disease.

$P=0.23$.

The patients were grouped as G1, G2, or G3 based on prior alcohol consumption patterns including 19 in G1 (alcohol intake $>20 \mathrm{~g} /$ day and $<40 \mathrm{~g} /$ day), 56 in G2 (alcohol intake $<20 \mathrm{~g} /$ day), and 57 in G3 (no alcohol intake). The clinical profile of these groups is shown in Table 1.

The relationship between histological diagnoses and levels of alcohol consumption is shown in Table 2. We could not detect significant differences between the level of ethanol consumption and the spectrum of histological types. No protective effect of light or moderate ethanol consumption was evident compared with abstainers among these severely obese patients. In contrast, there were significant differences in IR between the ethanol groups. Light consumption was associated with less IR compared with the abstainers or moderate drinkers $(P<0.05$, Table 3$)$. However, an association between the presence of IR and more severe NAFLD did not reach statistical significance (Table 4 ).

\section{Discussion}

In this study, light-to-moderate alcohol consumption did not correlate with the severity of NAFLD in morbidly obese patients undergoing bariatric surgery. Steatohepatitis (NASH) with fibrosis or ballooning, the most important forms of NAFLD, had a similar prevalence in patients with or without a history of light-to-moderate alcohol intake. Our results differed from those of Dixon et al. [13] who showed that moderate alcohol consump- tion seems to reduce the risk of NAFLD in the severely obese patients. They suggested that this could possibly be explained by the reduced IR in moderate alcohol consumption. Although we did detect improved IR with light ethanol consumption, this did not translate in improved histology.

The relatively high frequency of perisinusoidal fibrosis in the cases discussed herein could, in part, be because of the use of the Picrosirius staining method for collagen detection which has been shown to be more efficient than others in detection of early stages of fibrosis [14]. The presence of collagen in the perisinusoidal space is accepted as a marker of increased fibrogenesis in the liver even if it is present in a small amount as in our obese patients. Perisinusoidal fibrosis should be considered a surrogate of previous oxidative stress or inflammatory episode that induced liver stellate to produce collagen. In addition, the definition of moderate or light ethanol consumption remains controversial. It is possible that an undetected variation in ethanol consumption accounted for the differences that we observed. Similarly, it is possible that a more detailed dietary history to measure dietary composition more precisely could offer an explanation or that genetic factors could explain the observed differences. However, the absence of a clear protective effect in this population most clearly indicates a need for additional investigation.

A number of associations between alcohol consumption and MS or its individual components have been well documented $[13,15,16]$. In a cross-sectional study, that included 793 men and 315 women, the frequency of alcohol consumption was significantly lower among patients with MS than among those without MS (33.2 and $42.1 \%$ ) [15]. These data suggest that light alcohol consumption ameliorates some features of this syndrome. Several other studies have suggested that moderate alcohol intake improves insulin sensitivity and raises HDL-cholesterol [17-19]; but the issue remains controversial. In a cross-sectional study of 462 disease-free men, Meyer et al. [20] reported that an average consumption of alcohol was not associated with lower concentrations of HbA1C or fasting insulin.

Several possible mechanisms may explain the influence of alcohol intake on metabolic parameters. For example, alcohol may be metabolized in preference to other calorie sources, thus reducing glucose disposal and ethanol inhibits gluconeogenesis [21]. Other studies have suggested a U-shaped association between alcohol consumption and IR, similar to our results [13,22]. In accordance with these findings, higher levels of alcohol may reduce insulin binding and inhibit intracellular signaling related to insulin, but lower levels may be related to enhance sensitivity $[23,24]$. This issue may have importance on 
follow-up of obese people undergoing bariatric surgery. Dixon et al. [25] followed a group of severely obese patients after laparoscopic adjustable gastric-band surgery and found that hyperinsulinemia and increased IR are important predictors of a reduced rate of weight loss. In addition, those consuming alcohol lost weight at a greater rate than those who abstained.

Recently, Dunn et al. [26] evaluated the influence of modest wine drinking and decreased prevalence of NAFLD. The study included nondrinkers and modest wine drinkers and the conclusions were that modest wine consumption is associated with the reduced prevalence of suspected NAFLD.

In conclusion, our results suggest that light-to-moderate alcohol consumption may have a protection effect against IR in severely obese patients; however, it had no impact on the severity of activity and stage of liver disease. These data raise the question: Should light-to-moderate alcohol consumption be discouraged in severely obese patients? Maybe not, however, a word of caution is warranted and the level of alcohol consumption should be discussed with each patient to make them aware of the variation in the effects of ethanol in this setting.

\section{Acknowledgements}

This study was supported by the PAPES - CNPQ FIOCRUZ-BAHIA, no. 400267/2006-3.

Conflicts of interest: none declared.

\section{References}

1 Mokdad AH, Serdula MK, Dietz WH, Bowman BA, Marks JS, Koplan JP. The spread of the obesity epidemic in the United States, 1991-1998. JAMA 1999; 282:1519-1522.

2 World Health Organization. Obesity: preventing and managing the global epidemic. Report of a WHO consultation. World Health Organ Tech Rep Ser 2000; 894:i-xii, 1-253.

3 Australian Institute of Health and Welfare. Australia's Health 1998: the Sixth Biennial Health Report of the Australian Institute of Health and Welfare, 1998: 150-151 Australian Institute of Health and Welfare Canberra, Australia.

4 Flegal KM, Carroll MD, Kuczmarski RJ, Johnson CL. Overweight and obesity in the United States: prevalence and trends, 1960-1994. Int J Obes Relat Metab Disord 1998; 22:39-47.

5 Timar O, Sestier F, Levy E. Metabolic syndrome X: a review. Can J Cardiol 2000; 16:779-789.

6 Bell RA, Mayer-Davis EJ, Martin MA, D'Agostino RB Jr, Haffner SM. Associations between alcohol consumption and insulin sensitivity and cardiovascular disease risk factors: the insulin resistance and atherosclerosis study. Diabetes Care 2000; 23:1630-1636.
7 Keil U, Chambless LE, Doring A, Filipiak B, Stieber J. The relation of alcohol intake to coronary heart disease and all-cause mortality in a beer-drinking population. Epidemiology 1997; 8:150-156.

8 Bitencourt AG, Cotrim HP, Alves E, Almeida AM, Barbosa DBV, Santos AS D, et al. Doença hepática gordurosa não alcoólica: características clínicas e histológicas em obesos graves submetidos à cirurgia bariátrica (Nonalcoholic fatty liver disease: clinical and histological characteristics in obese who underwent bariatric surgery). Acta Gastroenterol Latinoam 2007; 37:224-230.

9 Guidorizzi de Siqueira AC, Cotrim HP, Rocha R, Carvalho FM, Freitas LAR Barreto $\mathrm{D}$, et al. Non-alcoholic fatty liver disease and insulin resistance: importance of risk factors and histological spectrum. Eur J Gastroenterol Hepatol 2005; 17:837-841.

10 Matteoni CA, Younossi ZM, Gramlich T, Boparai N, Liu YC, McCullough AJ. Nonalcoholic fatty liver disease: a spectrum of clinical and pathological severity. Gastroenterology 1999; 126:1413-1419.

11 Brunt EM, Neuschwander-Tetri BA, Oliver D, Wehmeier KR, Bacon BR. Nonalcoholic steatohepatitis: histologic features and clinical correlations with 30 blinded biopsy specimens. Hum Pathol 2004; 35:1070-1082.

12 Kleiner DE, Brunt EM, Van Natta M, Behling C, Contos MJ, Cummings OW, et al. Design and validation of a histological scoring system for nonalcoholic fatty liver disease. Hepatology 2005; 41:1313-1321.

13 Dixon JB, Dixon ME, O'Brien PE. Alcohol consumption in the severely obese: relationship with the metabolic syndrome. Obes Res 2002; 10:245-252.

14 Junqueira LCU, Bignoles G, Brentani RR. Picrosirius staining plus polarization microcopy, a specific method for collagen detection in tissue sections. Histochem J 1979; 11:447-455.

15 Lidfeldt J, Nyberg P, Nerbrand C, Samsioe G, Schersten B, Agardh CD. Socio-demographic and psychosocial factors are associated with features ofthe metabolic syndrome: the Women's Health in the Lund Area (WHILA) Study. Diabetes Obes Metab 2003; 5:106-112.

16 Rosell M, de Faire U, Hellenius ML. Low prevalence of the metabolic syndrome in wine drinkers: is it the alcohol beverage or the lifestyle? Eur $J$ Clin Nutr 2003; 57:227-234.

17 Solymoss BC, Bourassa MG, Lesperance J, Levesque S, Marcil M, Varga S, Campeau L. Incidence and clinical characteristics of the metabolic syndrome in patients with coronary artery disease. Coron Artery Dis 2003 14:207-212.

18 Hulley SB, Gordon S. Alcohol and high-density lipoprotein cholesterol: causal inference from diverse study designs. Circulation 1981; 64:57-63.

19 Kiechl S, Willeit J, Poewe W, Egger G, Oberhollenzer F, Muggeo M, Bonora E. Insulin sensitivity and regular alcohol consumption: large, prospective, cross sectional population study (Bruneck study). BMJ 1996 313:1040-1044.

20 Meyer KA, Conigrave KM, Chu NF, Rifai N, Spiegelman D, Stampfer MJ, Rimm EB. Alcohol consumption patterns and $\mathrm{HbA1c}, \mathrm{C}$-peptide and insulin concentrations in men. J Am Coll Nutr 2003; 22:185-194.

21 Shelmet JJ, Reichard GA, Skutches CL, Hoeldtke RD, Owen OE, Boden G. Ethanol causes acute inhibition of carbohydrates, fat, and protein oxidation and insulin resistance. J Clin Invest 1988; 81:1137-1145.

22 Lazarus S, Sparrow D, Weiss S. Alcohol intake and insulin levels. The Normative Aging Study. Am J Epidemiol 1997; 145:909-916.

23 Kiechl S, Willeit J, Poewe W, Egger G, Oberhollenzer F, Muggeo M, Bonora E. Insulin sensitivity and regular alcohol consumption: large, prospective, cross-sectional population study. BMJ 1996; 313:1040-1044.

24 Singh SP, Kumar Y, Snyder AK, Ellyin FE, Gilden JL. Effect of alcohol on glucose tolerance in normal and noninsulin-dependent diabetic subjects. Alcohol Clin Exp Res 1988; 12:727-730.

25 Dixon JB, Dixon ME, O'Brien PE. Pre-operative predictors of weight loss at 1-year after lap-band surgery. Obes Surg 2001; 11:200-207.

26 Dunn W, Xu R, Schwimmer JB. Modest wine drinking and decreased prevalence of suspected nonalcoholic fatty liver disease. Hepatology 2008; 47:1947-1954. 